\title{
Study of frequency response in power system with renewable generation and energy storage
}

DOI:

10.1109/PSCC.2016.7540912

\section{Document Version}

Accepted author manuscript

Link to publication record in Manchester Research Explorer

\section{Citation for published version (APA):}

Adrees, A., \& Milanovic, J. V. (2016). Study of frequency response in power system with renewable generation and energy storage. In Power Systems Computation Conference (PSCC), 2016

https://doi.org/10.1109/PSCC.2016.7540912

\section{Published in:}

Power Systems Computation Conference (PSCC), 2016

\section{Citing this paper}

Please note that where the full-text provided on Manchester Research Explorer is the Author Accepted Manuscript or Proof version this may differ from the final Published version. If citing, it is advised that you check and use the publisher's definitive version.

\section{General rights}

Copyright and moral rights for the publications made accessible in the Research Explorer are retained by the authors and/or other copyright owners and it is a condition of accessing publications that users recognise and abide by the legal requirements associated with these rights.

\section{Takedown policy}

If you believe that this document breaches copyright please refer to the University of Manchester's Takedown Procedures [http://man.ac.uk/04Y6Bo] or contact uml.scholarlycommunications@manchester.ac.uk providing relevant details, so we can investigate your claim.

\section{OPEN ACCESS}




\title{
STUDY OF FREQUENCY RESPONSE IN POWER SYSTEM WITH RENEWABLE GENERATION AND ENERGY STORAGE
}

\author{
Atia Adrees and J. V. Milanović \\ University of Manchester \\ Manchester, UK \\ atia.adrees@manchester.ac.uk,milanovic@manchester.ac.uk
}

\begin{abstract}
This paper presents the first comparative analysis of frequency support provided by a large-scale bulk energy storage system (ESS) against distributed ESS in a large meshed network. In IEEE 16 machine network, $30 \%$ of synchronous generation is replaced by renewables (RES). The analysis is further extended to investigate the effect of increased penetration of RES and reduction in inertia by decreasing synchronous generation at low network loading conditions for both types of ESS arrangements.
\end{abstract}

Keywords: Large-scale energy storage, distributed storage, frequency excursions, frequency nadir

\section{INTRODUCTION}

Maintaining the frequency of electric power systems at its nominal value requires a balance between power generation and power consumption. A certain amount of active power, generally termed frequency control reserve, is kept available to implement this control. The positive frequency control reserve supplies active power to compensate for a drop in the frequency. The deployment of negative frequency control reserve helps to lower the frequency.

Three levels of control are generally used to keep the balance between load and generation [1-4]. Primary frequency control is a local automatic control that regulates the active power generation to counteract frequency variations $[2,5]$. In particular, it is planned to stabilize the frequency following large generation or load outages. All synchronous generators are fitted with speed governor system to perform this control automatically. It is thus essential for the stability of the power system.

Secondary frequency control is an automatic centralized control that adjusts the frequency to the specified nominal value and maintains power flow between two areas at the scheduled values by adjusting the output of selected generators $[2,4]$. In other words, primary frequency control limits frequency excursions and secondary frequency control brings the frequency back to its nominal value.

Tertiary frequency control includes manual changes in the dispatching and commitment of generating units. This control is used to restore the primary and secondary frequency control reserves, to deal with congestions in the transmission network, and to bring frequency back to nominal value when secondary control is unable to complete this task.
One of the essential features of the low-carbon electric power system is the high penetration of renewable energy sources. Wind generation is a major technology of generating electric power with zero carbon dioxide emission. It is predicted that by 2020 the total worldwide power generated by wind generation would be more than $400 \mathrm{GW}$ which can supply about $12 \%$ of total worldwide electricity demand [6].

In new wind power installations Type 3 doubly fed induction generators (DFIGS) and Type 4 full converter connected generators have replaced the older constant speed squirrel cage induction generators [7]. Normally, variable speed wind turbines do not contribute to system inertia since the rotor of the variable speed wind turbines is running at a variable asynchronous speed and thus not sensitive to the change of system frequency [8, 9]. The continuous replacement of synchronous generation by renewable energy sources reduces the inertia of the system and primary frequency response provided by governors [10-12]. Therefore, frequency regulation has been the focus of many studies during last decade [10, 12, 13].

Studies are performed by National Grid, UK transmission operator, to investigate the effect of reduced inertia on the rate of change of frequency during large active power disturbances. An equivalent model of UK was used to analyze the frequency response at various inertia levels. The obtained results validated that inertia levels of the network significantly affect the rate of change of frequency in UK power networks [14].

Lawrence Berkeley National Laboratory California performed studies to assess the level of renewable resources that can be reliably added to the power grid. The results show that lower system inertia would increase the requirements for primary frequency control reserves to arrest frequency at the same nadir following the sudden loss of generation [15].

Research results and practical installations have demonstrated that energy storage system (ESS) can provide frequency regulation [16-18]. Many studies are performed to determine the optimal capacity and placement of ESS based on economic analysis [18-20]. A number of publications proposed methodologies for optimal capacity and placement by considering network constraints with DC and AC power flow.

This paper provides the first detailed analysis of the system frequency in a large meshed network with $30 \%$ 


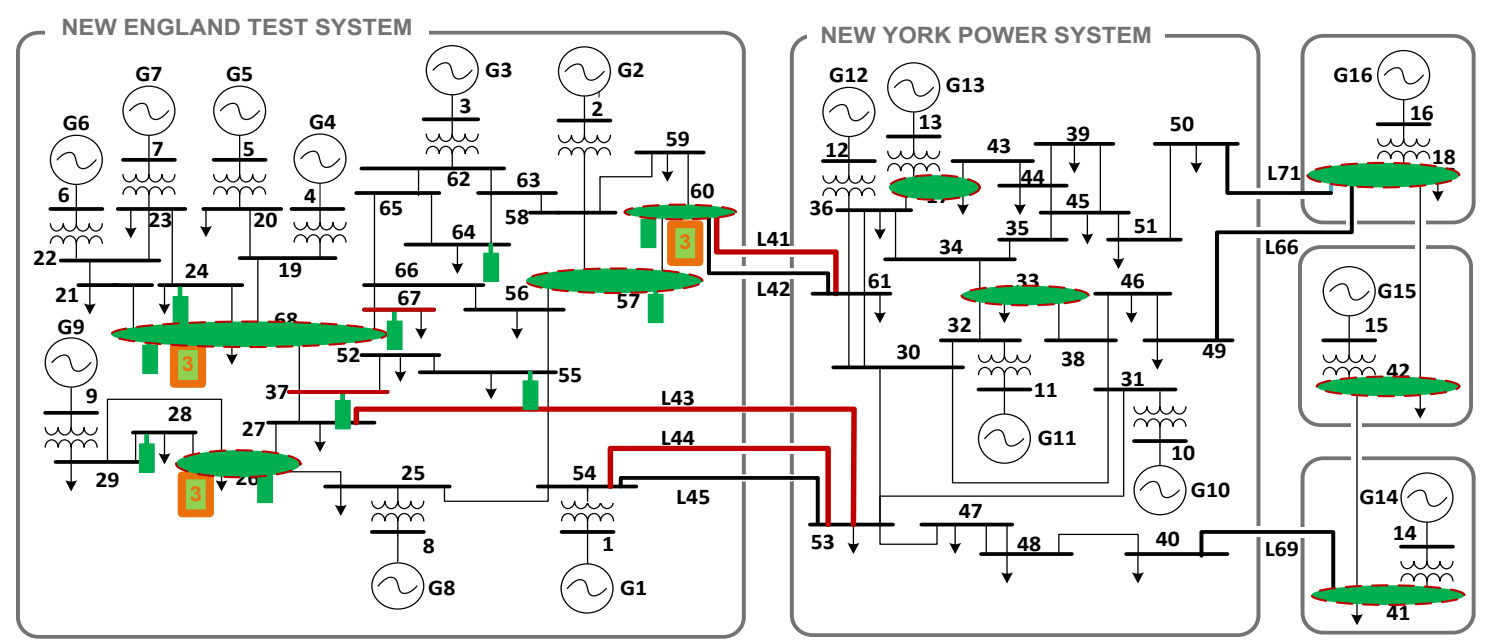

Fig. 1:16 machine, 68 bus test system with $30 \%$ renewables in each area and energy storage systems

renewable energy sources. Case studies investigate the frequency response of the system without ESS and with a large scale bulk ESS and distributed ESS of the same capacity. These studies demonstrate the difference in frequency support depending on the EES arrangement. Studies are performed for two loading levels of the network. For lower loading level, the total generation in the network is reduced by making some of synchronous generation offline. This decreases the amount of online synchronous generation resulting in a reduction in system inertia and increases the \% penetration of renewables. These studies clearly establish the effect of reduction in inertia due to increased penetration of renewables and extent of the frequency support provided by the large scale bulk and distributed ESS.

\section{TEST NETWORK}

The test system is a modified version of a reduced order equivalent model of New England Test System (NETS) and New York power system (NYPS), presented in Fig. 1. The network consists of 16 machines, 68 buses, and five distinct areas. NETS includes generators G1-G9, NYPS consists of G10-G13 and three neighboring areas are represented by generators G14, G15, and G16. G9 is equipped with fast-acting static exciter (IEEE STIA) and power system stabilizer (PSS). All other generators in the network are under slow excitation (IEEE DC1A). All generators in the network include speed governor systems. Generator G1 comprises GAST speed governor; G3 and G9 include IEEEG3 (hydro turbine) and G2-G8, G10-G16 incorporate IEEEG1 (steam turbine). The synchronous generators are represented by sixth order models. Transmission lines are modeled with the standard $\pi$ circuit.

Two types of RES model are introduced in the network, Type 3 doubly fed induction generators (DFIGs) and Type 4 Full converter Connected (FCC) units. 30\% of the generation in each of five areas is replaced by renewables (RES), comprising $21 \%$ of type 3 doubly fed Induction generators (DFIG) and 9\% type 4 full converter connected (FCC) units. In NETS, RES are connected to buses 26, 57 and 68, in NYPS at buses 33 and 37 and in surrounding areas at buses 18, 41 and 42 .

The network is modelled in DIgSILENT PowerFactory.

\subsection{Type 3 DFIG Modelling}

In this work, wind turbines are modelled as Type 3 doubly Fed Induction generators (DFIGs) with rotor side converter.

The model used for DFIGs is a generic WT (wind turbine) Type 3 model suitable for system stability studies. The modelling approach is similar to two recent working groups WECC [21] and IEC[22].

DFIG model takes into consideration the aerodynamic part and the drive train, the mechanical side of the converter. The model comprises the pitch control of turbine blades. The electrical controls that define the control of the active and reactive power of the unit are modeled appropriately. The induction generator model includes the rotor flux transients but neglects the stator flux transients which is common practice in power stability analysis [22]. The rotor side converter protection for over and under speed, over and under voltage limits are also modeled by representing crowbar system.

\subsection{Type 4 Full Converter Connected (FCC) Unit Modelling}

Type 4 WTG are full converter connected (FCC) generators. Any generator connected to the grid through full converter interface like PVs can also be represented by Type 4 WTG model for system stability studies [21]. This is appropriate for system stability studies since the converter decouples the mechanical dynamics of the unit from the electric grid [23, 24]. The model employed within these studies is Type 4 WTG generic model provided in DIgSILENT PowerFactory. The modelling approach is similar to Type 4 models presented in $[21,22]$. Current controller, PQ controller and over frequency power reduction control of the converter 
are also included in the model.

\subsection{Battery Energy Storage Systems (BESS)}

Fig. 2 shows the BESS model used within this work. The battery is modeled as a voltage source with internal impedance. The battery voltage varies linearly with state of charge (SOC), and the internal resistance is assumed to be constant.

With these assumptions, the battery model can be expressed as (1)

$$
U_{D C}=U_{\max } S O C+U_{\min }(1-S O C)-I Z_{i}
$$

$\boldsymbol{U}_{\boldsymbol{D C}}$ is the terminal DC voltage of the battery, $\boldsymbol{I}$ is the charge/discharge current, $\boldsymbol{U}_{\text {max }}$ and $\boldsymbol{U}_{\text {min }}$ are the voltage of the fully charged and discharged cell respectively. $\boldsymbol{Z}_{\boldsymbol{i}}$ is the battery internal resistance and $\boldsymbol{S O C}$ is the state of charge of the battery.

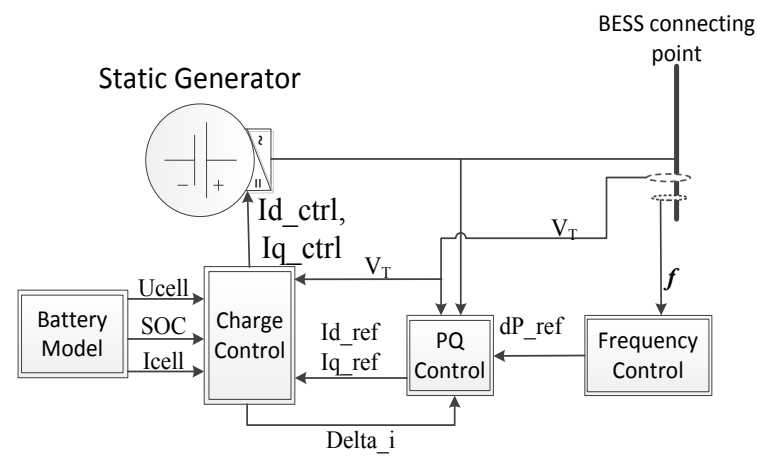

Fig. 2: BESS configuration with control scheme

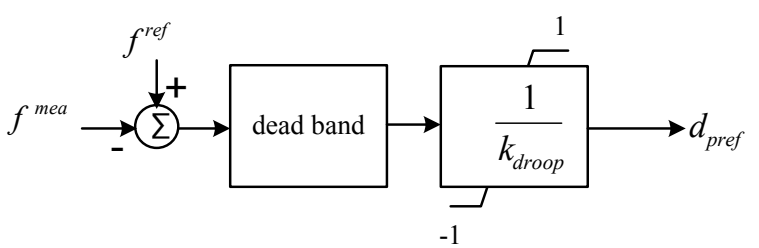

Error! Not a valid bookmark self-reference.Fig. 3: Frequency droop of BESS

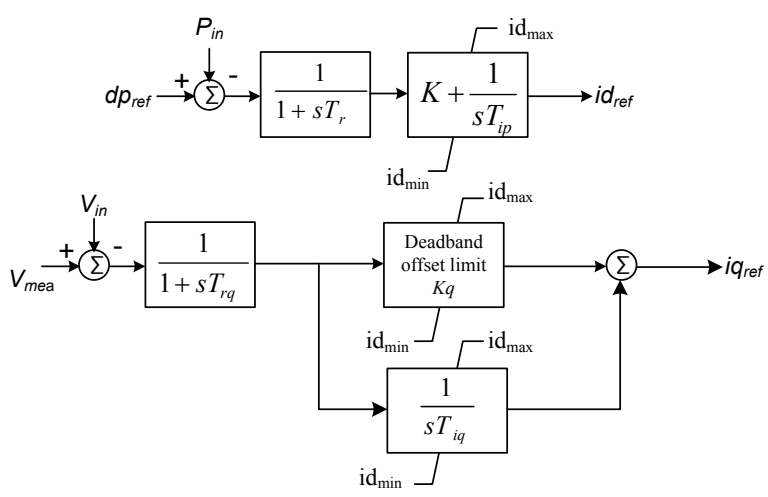

Fig. 4: PV control of BESS

BESS supplies/absorbs active to/from the grid when the system frequency deviates from the nominal value. The frequency control of BESS consists of a droop control presented in Fig. 3. The frequency control defines active power reference signal corresponding to frequency deviation measured at the point of connection of BESS. Battery energy storage system has PV control, presented in Fig. 4. Active power control is PI control and voltage control is a slow integrator. The parameters of frequency droop control and PV control are presented in Table I.

Table I: Frequency droop and PV control Parameters

\begin{tabular}{cccc}
\hline Parameter & Units & Description & Values \\
\hline \hline droop & {$[\mathrm{pu} / \mathrm{pu}]$} & Droop for frequency control & 0.004 \\
\hline $\mathrm{db}$ & {$[\mathrm{pu}]$} & $\begin{array}{c}\text { Deadband for frequency } \\
\text { control }\end{array}$ & 0.0002 \\
\hline $\mathrm{Tr}$ & {$[\mathrm{s}]$} & $\begin{array}{c}\text { Filter time constant, active } \\
\text { power }\end{array}$ & 0.01 \\
\hline Trq & {$[\mathrm{s}]$} & $\begin{array}{c}\text { Filter time constant, reactive } \\
\text { power }\end{array}$ & 0.1 \\
\hline $\mathrm{K}_{\mathrm{p}}$ & {$[\mathrm{pu}]$} & Proportional gain-id-PI control & 2 \\
\hline $\mathrm{K}_{\mathrm{q}}$ & {$[\mathrm{pu}]$} & Proportional gain-iq-PI control & 1 \\
\hline $\begin{array}{c}\text { AC- } \\
\text { deadband }\end{array}$ & {$[\mathrm{pu}]$} & $\begin{array}{c}\text { Dead band for proportional } \\
\text { gain }\end{array}$ & 0 \\
\hline Tip & {$[\mathrm{s}]$} & $\begin{array}{c}\text { Integrator time constant - ip } \\
\text { control }\end{array}$ & \\
\hline Tiq & {$[\mathrm{s}]$} & $\begin{array}{c}\text { Integrator time constant }- \text { iq } \\
\text { control }\end{array}$ & 0.002 \\
\hline id_min & {$[\mathrm{pu}]$} & Maximum discharging current & -1 \\
\hline iq_min & {$[\mathrm{pu}]$} & Minimum reactive current & -1 \\
\hline id_max & {$[\mathrm{pu}]$} & Maximum charging current & 1 \\
\hline iq_max & {$[\mathrm{pu}]$} & Maximum reactive current & 1 \\
\hline & & &
\end{tabular}

\section{ANALYSIS AND RESULTS}

It has to be noted that it is the general practice in frequency stability analysis to look at the collective performance of all generators in the network. The coherent response from all generators to changes in system load is assumed, and all generators in the network are aggregated into an equivalent generator. This equivalent generator has an inertia constant equal to the sum of the inertia constants of all generators, and it is driven by the combined mechanical outputs of the individual turbines. The effects of the system loads are lumped into a single damping constant $D$. The speed of the equivalent generator represents the system frequency. Fig. 5 shows the system equivalent for frequency studies. Fig. 6 presents typical frequency response observed in such system following a large active power disturbance.

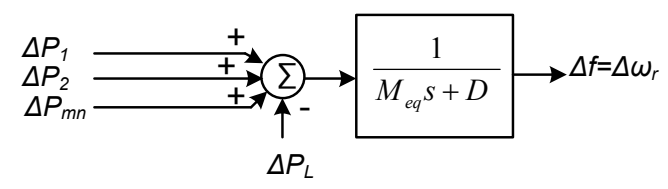

Fig. 5: System equivalent for frequency studies 
The rate of change of frequency in the system is given by (2)

$$
\frac{\partial f}{\partial t}=\frac{\Delta P_{L}}{2 H}
$$

It is clear from (2) that the rate of change of frequency is directly proportional to change in active power and inversely proportional to inertia of the system. A power system with a lower inertia will experience a larger frequency drop compared to the system with high inertia levels.

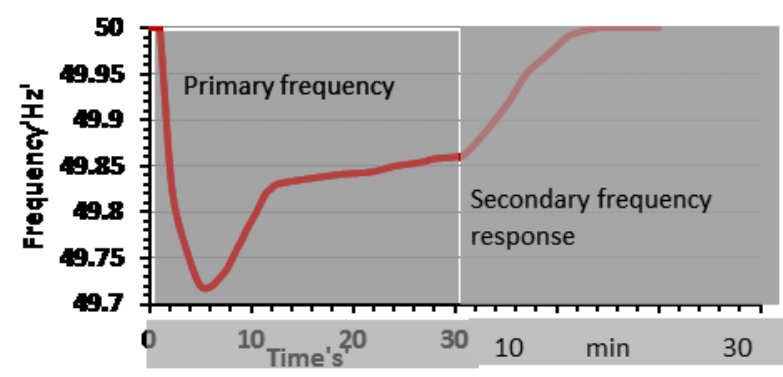

Fig. 6: Typical frequency response of a power system

The aim of these studies is to compare the frequency support provided by different modes of deployment of energy storage system in the power network. Therefore, the test system presented in Fig. 1 is used instead of an equivalent model for the network.

\subsection{Effect of reduction of system inertia on frequency nadir}

The inertia constant of a synchronous generator $H_{\text {gen }}$ defines its response to any changes in power balance. It is determined by the ratio between the kinetic energy stored in the rotating mass of the machine and the generator power rating $\boldsymbol{S}_{\text {rated }}$ given by (3)

$$
H_{\text {gen }}=\frac{1}{2} \frac{\mathrm{J} \omega^{2}}{S_{\text {rated }}}
$$

Considering (3), it is possible to calculate the average inertia $\boldsymbol{H}_{\text {sys }}$ of a power network. $\boldsymbol{H}_{\text {sys }}$ is defined in (4), where $\boldsymbol{H}_{\boldsymbol{i}}, \boldsymbol{S}_{\boldsymbol{i}}$ and $\boldsymbol{n}$ denote the inertia constant of the each generator, the generator rating and the number of units respectively.

$$
H_{\text {sys }}=\frac{\sum_{i=1}^{n} S_{i} H_{i}}{\sum_{i=1}^{n} S_{i}}
$$

The system inertia $\boldsymbol{H}_{\text {sys }}$ of 16 machine system, presented in Fig. 1, with nominal loading as given in [25] is calculated using (4).

$\boldsymbol{H}_{\text {sys }}$ of the system is calculated when $30 \%$ of synchronous generation in each area is replaced by renewables, in this case (4) is slightly modified

$$
H_{s y s}=\frac{\sum_{i=1}^{n} S_{i} H_{i}}{\sum_{i=1}^{n} S_{i}+S_{\text {res }}}
$$

Where $S_{\text {res }}$ is MVA ratings of renewables.

In future networks, most challenging periods for frequency control can be during off-peak hours. At the lower loading of the network when fewer synchronous generators are online, and the relative penetration level of renewables is higher. During these period a system would have low system inertia and a few power plants available to provide frequency response services $[26$, 27].

To simulate this type of scenario, loading of the network is reduced to $60 \%$, average loading of annual load duration curve. Generation from renewables is kept the same. $40 \%$ reduction in network power generation is achieved by making $55 \%$ of synchronous generation offline. This increases the \% penetration of renewables to 55 and reduces synchronous generation to 45 . The system inertia using (3) is also calculated for this scenario.

$\boldsymbol{H}_{\text {sys }}$ of the studied network with no renewables in the network is $7.95 \mathrm{~s}$. Replacement of $30 \%$ of synchronous generation by renewables reduces $\boldsymbol{H}_{\text {sys }}$ to $6.4 \mathrm{~s}$, $20 \%$ reduction in system inertia. At $60 \%$ loading when $55 \%$ of synchronous generation goes offline, $\boldsymbol{H}_{\text {sys }}$ decreases to $5.26 \mathrm{~s}$. This leads to $34 \%$ reduction in system inertia.

NYPS imports power from NETS through five interconnections, L41, L42, L43, L44 and L45.

The effect of reduction in inertia on frequency excursions on interconnections between NETS and NYPS areas is studied by introducing the same size active power disturbance in the network for three following scenarios

1) Nominal loading with no renewables in the network, system inertia $\boldsymbol{H}_{\boldsymbol{s y s}}$ is equal to $7.95 \mathrm{~s}$

2) Nominal loading, $30 \%$ renewables in the network, $\boldsymbol{H}_{\text {sys }}$ reduced by $20 \%$ to $6.4 \mathrm{~s}$.

3) 60 loading of the network, $55 \%$ penetration of renewables, $\boldsymbol{H}_{\text {sys }}$ decreased by $34 \%$ to $5.25 \mathrm{~s}$

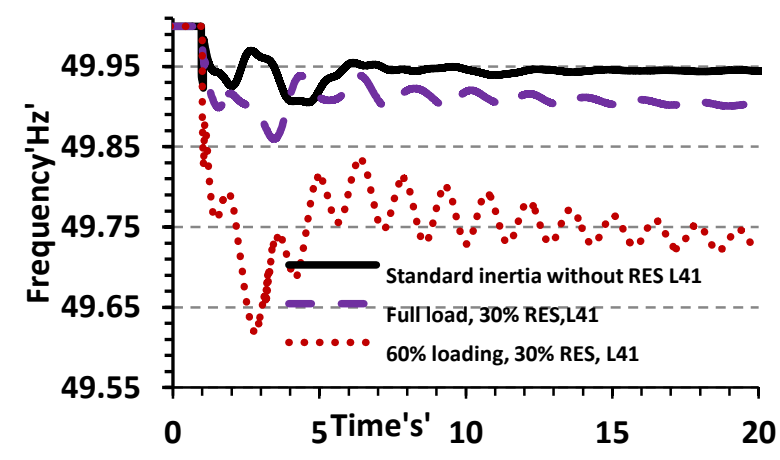

Fig. 7: Effect of reduction in inertia

Fig. 9Fig. 7 shows frequency excursions on L41 for three scenarios described above. Black solid line shows frequency excursions for the nominal loading of the network with standard inertia. Purple (small dashed line) represents frequency excursion on the same tie-line for the same size of active power disturbance when $30 \%$ 
synchronous generation is replaced by renewables. Red (dotted line) shows frequency excursions when network loading is reduced to $60 \%$.

It is to be noted that Fig. 7 has superimposed lower frequency oscillations since the test network has generators and transmission lines. In Fig. 8 the typical frequency response (solid black line) and filtered frequency response with nominal loading and $30 \%$ RES on tie-line L41 (small dashed red line) are plotted. It can be observed that underlying frequency response of Fig. 9 is very similar to typical frequency response and capable to capture, frequency nadir and ROCOF, essential frequency response parameters.

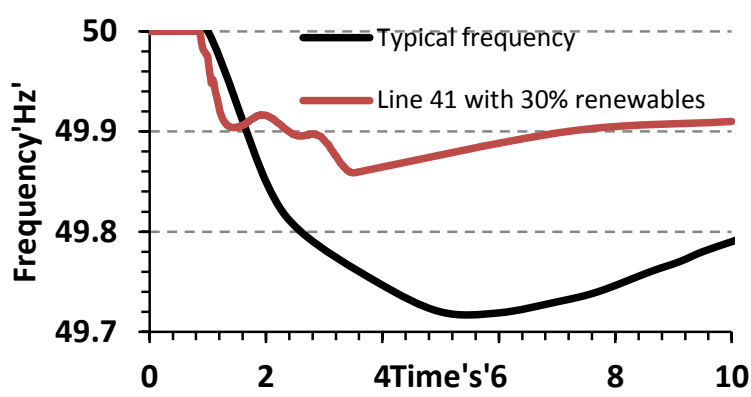

Fig. 8: Typical frequency response and frequency response in multimachine network

It can be seen from Fig. 7 as expected that frequency nadir value is lowered with reduction of inertia. The ROCOF also increases as network inertia decreases. Frequency nadir occurs earlier with a reduction in inertia.

Table II: Effect of reduction in inertia on frequency parameters

\begin{tabular}{cccc}
\hline & $\begin{array}{c}\text { Frequency } \\
\text { nadir } \\
\text { 'Hz' }\end{array}$ & $\begin{array}{c}\text { ROCOF } \\
\text { 'Hz/s's }\end{array}$ & $\begin{array}{c}\text { Time of frequency } \\
\text { nadir occurrence } \\
\text { 's' }\end{array}$ \\
\hline \hline $\begin{array}{c}\text { Standard inertia } \\
\text { No RES }\end{array}$ & 49.9 & 0.029 & 4.47 \\
\hline $\begin{array}{c}20 \% \text { reduction } \\
30 \% \text { RES }\end{array}$ & 49.86 & 0.063 & 3.4 \\
\hline $\begin{array}{c}34 \% \text { reduction } \\
55 \% \text { RES }\end{array}$ & 49.62 & 0.22 & 2.7 \\
\hline
\end{tabular}

It can be observed from Fig. 7 and Table II that the change in frequency nadir and ROCOF is not linear with $\%$ penetration of renewable and reduction in inertia.

For first $20 \%$ reduction in inertia and $30 \%$ penetration of RES, frequency nadir drops from $49.9 \mathrm{~Hz}$ to 49.86 and ROCOF increases from $0.029 \mathrm{~Hz} / \mathrm{s}$ to 0.063 $\mathrm{Hz} / \mathrm{s}$.

At $60 \%$ loading when inertia of the system reduces by $34 \%$ and $\%$ penetration of RES increases to $55 \%$; frequency nadir drops to 49.62 and ROCOF increases to $0.22 \mathrm{~Hz} / \mathrm{s}$.

In first a few seconds following the loss of power generation, grid frequency starts to drop. These initial frequency dynamics are dominated by the inertial response of the generators that remain online. The synchronous generators release their stored kinetic energy into the system, reducing the initial rate of change of frequency (ROCOF) and allowing slower governor action to catch up and contribute to frequency arrest. As the number of online synchronous generator decreases, not only system inertia decreases, primary frequency control provided by the system also reduces. Therefore, at $60 \%$ loading a bigger drop in frequency nadir is observed.

\subsection{Effect of different modes of deployment of ESS on Frequency nadir}

To compare different modes of deployment of ESS on frequency excursions three case studies are performed

1) One large ESS of $1000 \mathrm{MW}$ is placed on bus 60. Frequency excursions due to a simultaneous outage of generator G7 and generator G10 are recorded on each interconnection between NETS and NYPS.

2) One large ESS is replaced by three ESSs, one 400MVA BESS connected at bus 60 and two 300MVA connected at buses 37 and 21. The total capacity of energy storage in NETS area stays 1000MVA.

3) A 100MVA ESS is connected at each of following buses, 21, 24, 26, 28, 37, 55, 58, 59, 64 and 67. Frequency excursions caused by the same disturbance, simultaneous outage of $\mathrm{G} 7$ and $\mathrm{G} 10$, are recorded.

\subsubsection{Nominal loading and 30\% RES}

Above described three study cases are performed in the network with the nominal loading and when 30\% synchronous generation is replaced by RES.

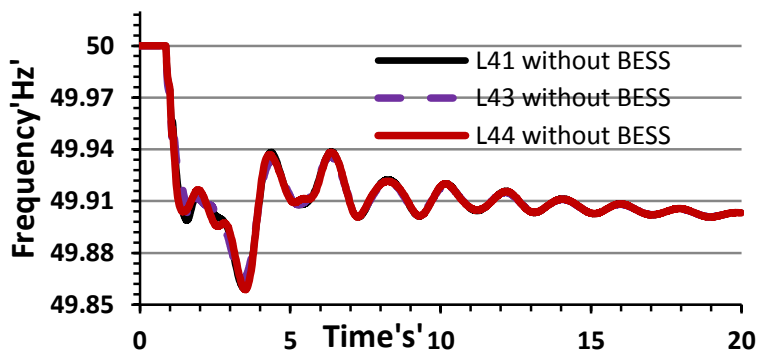

Fig. 9: Frequency excursions at interconnections between NYPS and NETS

Fig. 9 shows frequency excursions on tie-lines without energy storage. It can be observed that value and time of occurrence of frequency nadir are the same for all tie-lines between NETS and NYPS.

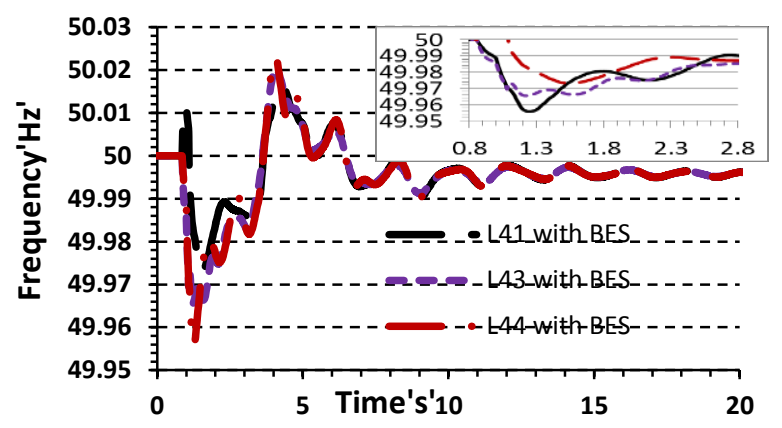

Fig. 10: Frequency excursions at interconnections between NYPS and NETS with one ESS 
Fig. 10 shows frequency excursions on tie-lines L41, L43 and L44 with one large ESS on bus 60. It can be seen that frequency nadir on each of tie-lines between NETS and NYPS has improved significantly when ESS is placed on bus 60. Close inspection of Fig. 9 and Fig. 10 reveals that frequency nadir is slightly different on L41, L43 and L44 with ESS while it has the same value without ESS.

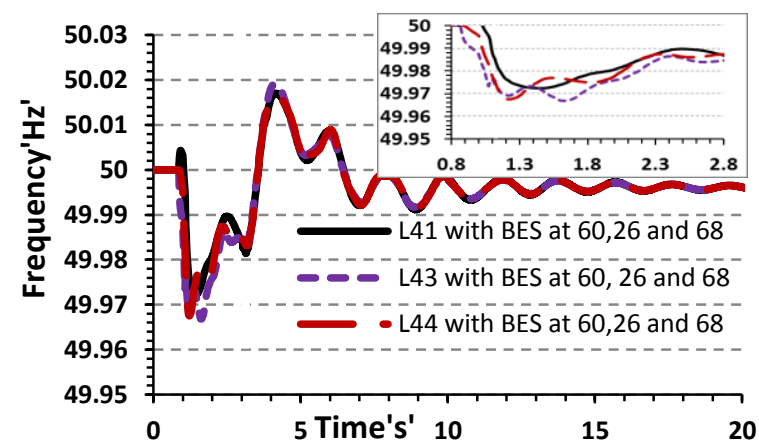

Fig. 11: Frequency excursions at interconnections between NYPS and NETS with three ESS

Fig. 11 shows frequency excursion on the same tielines for the same active power disturbance when a large ESS is replaced by three ESS in NETS area. A quick glance at Fig. 11, indicate that frequency nadir is nearly the same on each tie-line.

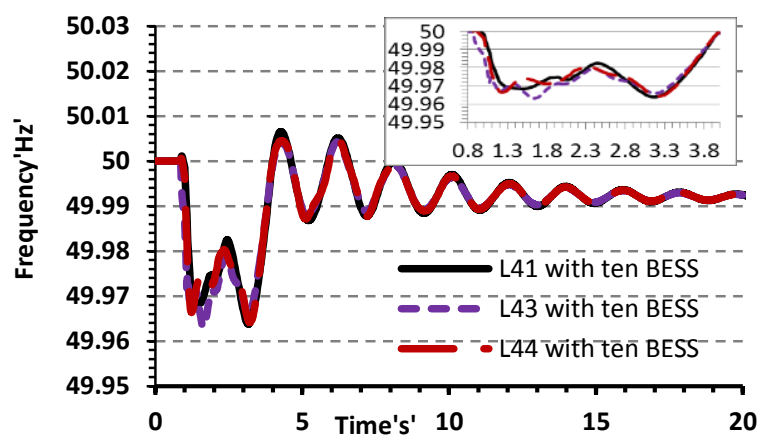

Fig. 12: Frequency excursions at interconnections between NYPS and NETS with ten ESS

Fig. 12 presents frequency excursions on tie-lines L41, L43 and L44 when three ESS are replaced by ten ESS in the same area. The total storage capacity remains the same. It can be seen that value of frequency nadir is nearly the same on L41, L43 and L44.

\section{$3.2 .260 \%$ loading of the network}

As explained above at $60 \%$ loading of the network, the power generation from RES is kept as it was for the nominal loading. $40 \%$ reduction in network generation is achieved by making $55 \%$ of synchronous generation offline; this increases \% generation contribution from RES to $55 \%$.

At $60 \%$ loading of the network without ESS, the frequency excursions due to the same size of generation loss $(\mathrm{G} 7+\mathrm{G} 10)$ are presented in Fig. 13.

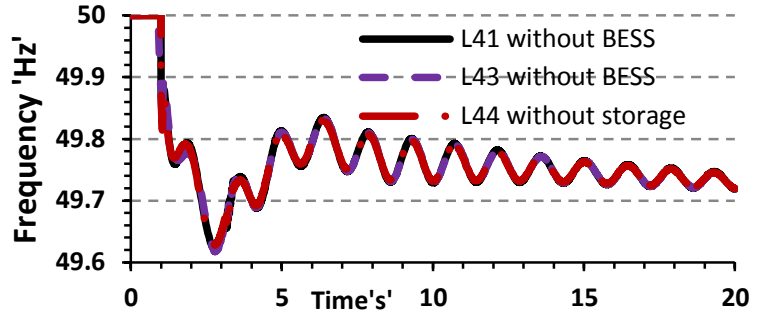

Fig. 13: Frequency excursions at interconnections between NYPS and NETS

It can be observed that the value and time of occurrence of frequency nadir are the same for L41, L43 and L44.

Fig. 14 shows frequency excursions at three studies interconnections with one large ESS. It can be observed that frequency nadir is improved from $49.62 \mathrm{~Hz}$ to $49.94 \mathrm{~Hz}$. The value and time of occurrence of frequency nadir are the same for each tie-line between NETS and NYPS.

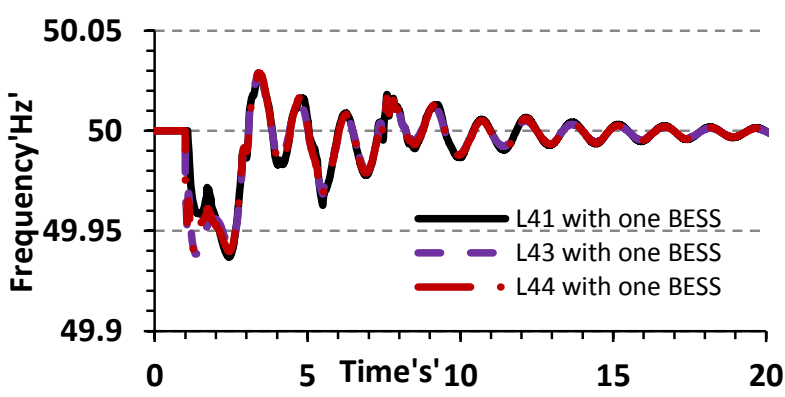

Fig. 14: Frequency excursions on tie-lines with one ESS for $60 \%$ loading of the network

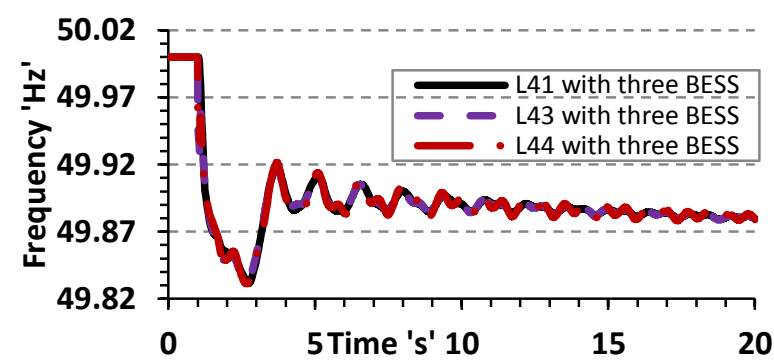

Fig. 15: Frequency excursions on tie-lines with three ESS for $60 \%$ loading of the network

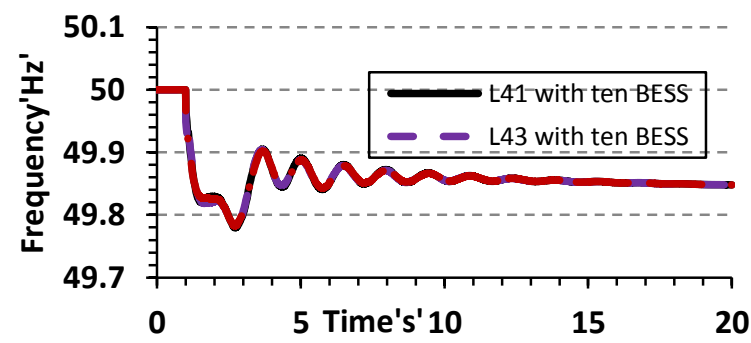

Fig. 16: Frequency excursions on tie-lines with ten ESS for $60 \%$ loading of the network

Fig. 15 shows frequency excursions when one large ESS in NETS is replaced by three ESS in NYPS area. It can be observed that frequency nadir drops from 49.94 $\mathrm{Hz}$ to $49.83 \mathrm{~Hz}$. The improvement in frequency nadir is 
reduced when one ESS is replaced by three ESS in the system.

Fig. 16 presents frequency excursions with $10 \mathrm{ESS}$, the total storage capacity in NETS area remains the same. It can be seen that frequency nadir is further dropped from $49.83 \mathrm{~Hz}$ to $49.78 \mathrm{~Hz}$ when the size of BESS reduces to $100 \mathrm{MVA}$, and a number of BESS increases to ten.

\section{CONCLUSIONS}

This paper presented the first comparison of frequency support provided by o bulk large-scale ESS and distributed energy storage.

The results of studies demonstrate that at lower penetration level of RES the frequency support provided by a large- scale and distributed ESS is not considerably different. The improvement in frequency nadir is nearly the same with one large- scale ESS and distributed ESS. The analysis shows that when there is less synchronous generation in the network and \% of RES increase to $55 \%$, the frequency support provided by a single- large ESS is superior than the distributed ESS. It is observed that as the number of ESS increases the improvement in frequency nadir decreases.

The paper also demonstrated that the decrease in frequency nadir and the increase in ROCOF is not linear with a reduction in inertia and \% penetration of RES. The results of analysis also indicate that network could exhibit severe frequency excursions at lower loading levels when less synchronous generation is online and $\%$ active power contribution from RES is increased more than $50 \%$.

\section{REFERENCES}

Chang-Chien Le-Ren, Hoonchareon Chee-Mun, and R. A. Kramer, "Estim:

(c) Ong adaptive frequency bias setting in load frequency control," Power Systems, IEEE Transactions on, vol. 18, pp. 904911, 2003.

[2] P.Kundur, Power System Stability \& Control. New York London: McGraw Hill, 1994

[3] J. W. Ingleson and D. M. Ellis, "Tracking the Eastern interconnection frequency governing characteristic," in IEEE Power Engineering Society General Meeting, 2005. 2005, pp. 1461-1466 Vol. 2.

[4] Y. G. Rebours, D. S. Kirschen, M. Trotignon, and S. Rossignol, "A Survey of Frequency and Voltage Control Ancillary Services\&mdash;Part I: Technical Features," IEEE Transactions on Power Systems, , vol. 22, pp. 350357, 2007.

A. J. Wood and B. F. Wollenberg, Power Generation, Operation and Control, 2nd ed. New York: Wiley, 1996.

Wind force 12, "A blueprint to achieve $12 \%$ of the world's electricity from wind power by 2020," GWEC 2005.

J. Quintero, V. Vittal, G. T. Heydt, and Zhang Hui, "The Impact of Increased Penetration of Converter ControlBased Generators on Power System Modes of Oscillation," IEEE Transactions on Power Systems, , vol. 29, pp. 22482256, 2014

G. Lalor, A. Mullane, and M. O'Malley, "Frequency control and wind turbine technologies," IEEE Transactions on Power Systems, , vol. 20, pp. 1905-1913, 2005.

[9] M. Reza, J. Morren, P.H. Schavemaker, W.L. Kling, and L. van der Sluis, "Power electronic interfaced DG units: impact of control strategy on power system transient stability," presented at the IET Conference Proceedings, 2005.

[10] T. Weissbach and E. Welfonder, "High frequency deviations within the European Power System: Origins and proposals for improvement," in IEEE/PES Power Systems Conference and Exposition, 2009. PSCE '09. , 2009, pp. 16.

[11] H E Joseph et al, "Use of frequency response metrics to assess the planning and operating requirements for reliable integration of variable renewable generation," Ernest Orlando Lawrence Berkeley National Laboratory, Berkeley,LBNL-4142E, Dec. 2010.

[12] J. W. Ingleson and D. M. Ellis, "Tracking the Eastern interconnection frequency governing characteristic," in IEEE Power Engineering Society General Meeting, 2005. 2005, pp. 1461-1466 Vol. 2.

[13] P. B. Eriksen, T. Ackermann, H. Abildgaard, P. Smith, W. Winter, and J. M. Rodriguez Garcia, "System operation with high wind penetration," Power and Energy Magazine, IEEE, vol. 3, pp. 65-74, 2005.

[14] J. McLoughlin, Y. Mishra, and G. Ledwich, "Estimating the impact of reduced inertia on frequency stability due to large-scale wind penetration in Australian electricity network," presented at the Australasian Universities Power Engineering Conference (AUPEC), 2014, 2014.

[15] H. E. Joseph, "Use of frequency response metrics to assess the planning and operating requirements for reliable integration of variable renewable generation," Ernest Orlando Lawrence Berkeley National Laboratory, LBNL4142E Dec. 2010.

[16] Helder Lopes Ferreira, Raquel Garde, Gianluca Fulli, Wil Kling, and Joao Pecas Lopes, "Characterisation of electrical energy storage technologies," Energy, vol. 53, pp. 288-298, 2013.

[17] S. K. Aditya and D. Das, "Application of battery energy storage system to load frequency control of an isolated power system," International Journal of Energy Research, vol. 23, pp. 247-258, 1999.

[18] P. F. Ribeiro, B. K. Johnson, M. L. Crow, A. Arsoy, and Y. Liu, "Energy storage systems for advanced power applications," Proceedings of the IEEE, vol. 89, pp. 17441756, 2001.

[19] Mohammad Reza Aghamohammadi and Hajar Abdolahinia, "A new approach for optimal sizing of battery energy storage system for primary frequency control of islanded Microgrid," International Journal of Electrical Power \& Energy Systems, vol. 54, pp. 325-333, 2014.

[20] Daniel Kottick and Moshe Blau, "Operational and economic benefits of battery energy storage plants," International Journal of Electrical Power \& Energy Systems, vol. 15, pp. 345-349, 1993.

[21] WECC Renewable Energy Modeling Task Force, "WECC Solar Plant Dynamic Modeling Guidelines," 2014.

[22] P. Sorensen, B. Andresen, J. Fortmann, and P. Pourbeik, "Modular structure of wind turbine models in IEC 6140027-1," presented at the IEEE Power and Energy Society General Meeting (PES), 2013.

[23] S. Eftekharnejad, V. Vittal, G. T. Heydt, B. Keel, and J. Loehr, "Impact of increased penetration of photovoltaic generation on power systems," IEEE Transactions on Power Systems, , vol. 28, pp. 893-901, 2013.

[24] J. Quintero, V. Vittal, G. T. Heydt, and Zhang Hui, "The Impact of Increased Penetration of Converter ControlBased Generators on Power System Modes of Oscillation," IEEE Transactions on Power Systems, vol. 29, pp. 22482256, 2014.

[25] P. Pal and B. Chauduri, Robust Control in Power Systems. New York: Springer Science \& Business Media, 2005.

[26] Wang Ye, G. Delille, H. Bayem, X. Guillaud, and B. Francois, "High Wind Power Penetration in Isolated Power Systems\&\#x2014;Assessment of Wind Inertial and Primary Frequency Responses," IEEE Transactions on Power Systems, vol. 28, pp. 2412-2420, 2013.

[27] A. I. Estanqueiro, J. M. Ferreira De Jesus, J. Ricardo, A. dos Santos, and J. A. Peas Lopes, "Barriers (and 


\section{ACCEPTED VERSION OF THE PAPER}

Solutions...) to Very High Wind Penetration in Power Systems," presented at the IEEE Power Engineering Society General Meeting, 2007. , 2007. 